\title{
Dietary intake of calcium and postmenopausal bone loss
}

\author{
John C Stevenson, Malcolm I Whitehead, Malcolm Padwick, Julie A Endacott, Cathy Sutton, \\ Linda M Banks, Chris Freemantle, Terry J Spinks, Richard Hesp
}

\begin{abstract}
The use of calcium supplements to prevent postmenopausal bone loss and hence osteoporosis is widespread, but the evidence for their efficacy, either alone or in combination with other treatments, is contradictory. Skeletal measurements and dietary intake of calcium were determined in 59 healthy postmenopausal women, most of whom were within five years of the menopause. No correlation was found between current intake of calcium and either total calcium in the body or the density of trabecular or cortical bone in the forearm or vertebral trabecular bone. Dietary intake of calcium did not influence the rate of postmenopausal bone loss in the 54 women who completed 12 months of active or placebo treatment. Even when extremes of calcium intake were examined no difference was found in bone measurements between the women with the highest and lowest intakes.
\end{abstract}

The results of this study suggest that the bone density of women in the early menopause is not influenced by current dietary intake of calcium.

NW8 9SO

John C Stevenson, $\mathrm{MB}$,

consultant endocrinologist

Academic Department of Gynaecology, King's College School of Medicine and Dentistry, London SE5 8RX

Malcolm I Whitehead, MRCOG, senior lecturer and consultant gynaecologist Malcolm Padwick, MB, research registrar

Julie A Endacott, SRN, research sister

Dietetics Department Mayday Hospital, Croydon, Surrey CR4 7YE

Cathy Sutton, BSC, dietician

Department of Diagnostic Radiology and MRC Cyclotron Unit, Hammersmith Hospital, London W12 0HS

Linda M Banks, DCR, superintendent radiographer

Chris Freemantle, BSC, scientific officer

Terry J Spinks, BSC, senior scientist

Division of Radioisotopes, Clinical Research Centre, Harrow, Middlesex

HA1 3UJ

Richard Hesp, BSC, member

of scientific staff

Correspondence to:

Dr Stevenson.

\section{Introduction}

Postmenopausal osteoporosis is one of the most common diseases of older women in the Western world and is responsible for considerable morbidity, mortality, and costs. ' Inadequate dietary intake of calcium has been suggested to cause this disease, ${ }^{2}$ and some studies have suggested that a high dietary intake of calcium will prevent postmenopausal bone loss and hence the development of osteoporosis. ${ }^{3+}$ Although other studies have failed to show a clear benefit of a high dietary intake of calcium, including large calcium supplements, on postmenopausal bone loss, ${ }^{56}$ calcium is promoted commercially as preventing osteoporosis, being given either as an alternative or as an adjunct to hormone replacement. ${ }^{\prime}$ These conflicting data have led to the importance of calcium intake being questioned. . $^{78}$

These previous studies have been incomplete because they did not selectively examine both cortical and trabecular bone in the axial and appendicular skeleton. Bone measurements in the appendicular cortical skeleton do not reflect accurately those in the axial trabecular skeleton. ${ }^{9}$ To examine the influence of dietary intake of calcium on bone in women early in the menopause and to assess any additive effect of calcium intake to treatments that may prevent bone loss we took regional skeletal measurements that independently assessed cortical and trabecular bone.

\section{Patients and methods}

Seventy postmenopausal women, all volunteers, were recruited and randomly allocated to one of four treatment groups. Six did not start the study, and five failed to complete their dietary questionnaires. Thus we studied 59 healthy white women (median age 54.9 years, range 37-64). Most were within five years of the menopause (median 3.5 years). None of the women was taking any drug known to affect calcium metabolism. A true postmenopausal state was confirmed in each woman by measurement of concentrations of circulating gonadotrophins (plasma follicle stimulating hormone $>40 \mathrm{IU} / \mathrm{l}$ ) and gonadal steroid hormone (plasma oestradiol $<70 \mathrm{pmol} / \mathrm{l}$ ). Five women in the groups given active treatment failed to complete the study.

As there was no significant bone loss during the study in any of the three groups given active treatment, whereas significant bone loss in vertebrae was seen in the group given a placebo (Student's paired $t$ test, $p=0.001$ ), the three active groups were combined as the treatment group. In the group given placebo 16 women applied inactive gel $5 \mathrm{~g}$ daily throughout the study to the skin of the abdomen and upper thighs and took three inactive tablets daily for the first 12 days of each calendar month. In the group given treatment 38 women took either synthetic human calcitonin (Cibacalcin, Ciba-Geigy; 20 IU three times a week by subcutaneous injection) or percutaneous oestradiol (Oestrogel, Besins-Iscovesco; $5 \mathrm{~g}$ (equivalent to $3 \mathrm{mg}$ $17 \beta$-oestradiol) daily) together with oral progesterone $300 \mathrm{mg}$ daily for 12 days each month, or both.

Total body calcium was measured by neutron activation analysis in vivo. ${ }^{10}$ Whole body calcium-49 was produced by irradiation with neutrons generated by a cyclotron and measured in a multicrystal whole body counter, the value being expressed as grams. The precision of measurement in vivo was about $3 \%$ and accuracy in vitro was $8 \%$. Total body calcium was measured only before treatment.

Vertebral trabecular bone density was measured by quantitative computed tomography. ${ }^{11}$ Three $4 \mathrm{~mm}$ slices were measured in the vertebral bodies of $\mathrm{L} 2-4$, and the mean value was expressed as $\mathrm{mg} / \mathrm{cm}^{3}$ by the simultaneous measurement of a mineral equivalent phantom. The precision of measurement in vivo was $2 \cdot 2 \%$ and accuracy in vitro was $2 \cdot 5 \%$.

Bone density in the dominant radius was measured with an ISOTOM computed tomography system, which incorporated an iodine- 125 source. ${ }^{12}$ The precision of measurement in vivo was about $2 \%$. Trabecular bone density was the mean linear attenuation coefficient of the central half of the cross section of bone measured at $8-10 \%$ of the distance from the ulnar styloid to the olecranon. The value was expressed per $\mathrm{cm}$. Cortical bone density was the product of the mean linear attenuation coefficient for the complete cross section of bone and the area measured at one third of the distance from the ulnar styloid process to the olecranon. The value was expressed as $\mathrm{cm}$. All measurements were carried out blind. Baseline measurements were expressed in absolute values and repeated measurements (at 12 months) as the percentage change from initial values. 
Dietary intake was assessed by questionnaire and interview. The calcium content of the dietary intake during a representative day was determined at the start of the study. None of the women made any major change in dietary calcium intake during the study, as assessed by further interview towards the end of the study. To allow for any inaccuracies in assessments of dietary calcium we compared bone measurements between the extremes of calcium intake, dividing both the placebo and active treatment groups into quartiles according to intake and defining the upper quartile as the group with a high calcium intake and the lower quartile as the group with a low calcium intake.

Pearson correlations were used to analyse the baseline data, and Spearman's rank correlations to analyse the relation of variables to changes in bone density. Mann-Whitney $U$ tests were used to examine differences between variables. Two tailed tests were used for all significances.

\section{Results}

There were no significant differences in any variable between the placebo and treatment groups and no significant correlations between dietary intake of calcium and any bone measurement (table I). When extremes of calcium intake were examined there were no significant differences in any bone measurement between the groups with low and high intakes (table II).

No correlation was seen between dietary calcium intake and any change in bone measurements in either

TABLE I-Correlation coefficients between dietary intake of calcium and total body calcium and bone density in postmenopausal women

\begin{tabular}{lcccc}
\hline & $\begin{array}{c}\text { Dietary intake } \\
\text { of calcium }\end{array}$ & $\begin{array}{c}\text { Total } \\
\text { body calcium }\end{array}$ & $\begin{array}{c}\text { Vertebral } \\
\text { bone density }\end{array}$ & $\begin{array}{c}\text { Forearm trabecular } \\
\text { bone density }\end{array}$ \\
\hline Total body calcium & $0 \cdot 03(\mathrm{n}=57)$ & & & \\
Vertebral bone density & $0 \cdot 13(\mathrm{n}=58)$ & $0 \cdot 53^{\star}(\mathrm{n}=56)$ & & \\
Forearm trabecular bone density & $-0.03(\mathrm{n}=56)$ & $0.63^{\star}(\mathrm{n}=54)$ & $0.48^{\star}(\mathrm{n}=55)$ & \\
Forearm cortical bone density & $0 \cdot 20(\mathrm{n}=57)$ & $0 \cdot 79^{\star}(\mathrm{n}=55)$ & $0^{*}+43^{\star}(\mathrm{n}=56)$ & $0 \cdot 48^{\star}(\mathrm{n}=56)$ \\
& & &
\end{tabular}

${ }^{\star} \mathrm{p}=0.001$ (Pearson correlation)

TABLE II-Mean (SEM) bone measurements in postmenopausal women with high and low intakes of calcium before and after treatment. Measurements obtained in 15 women in each group before treatment and 11 women after treatment

\begin{tabular}{|c|c|c|}
\hline & $\begin{array}{l}\text { Low intake } \\
\text { of calcium } \\
\text { (lower quartile) }\end{array}$ & $\begin{array}{l}\text { High intake } \\
\text { of calcium } \\
\text { (upper quartile) }\end{array}$ \\
\hline \multicolumn{3}{|l|}{ Daily intake of calcium $(\mathrm{mg})$ : } \\
\hline Before treatment & $530(43)$ & $1564(62)$ \\
\hline After treatment & $504(54)$ & $1621(77)$ \\
\hline Total body calcium before treatment $(\mathrm{g})$ & $766(20)$ & $781(21)$ \\
\hline \multicolumn{3}{|l|}{ Vertebral bone density: } \\
\hline Before treatment $\left(\mathrm{mg} / \mathrm{cm}^{3}\right)$ & $123(8)$ & $142(10)$ \\
\hline$\%$ Change after treatment & $3 \cdot 6(2 \cdot 3)$ & $-1 \cdot 0(1.5)$ \\
\hline \multicolumn{3}{|l|}{ Forearm trabecular bone density: } \\
\hline Before treatment $(/ \mathrm{cm})$ & $0.67(0.03)$ & $0.70(0.02)$ \\
\hline$\%$ Change after treatment & $1 \cdot 5(2 \cdot 0)$ & $-2 \cdot 1(1 \cdot 2)$ \\
\hline \multicolumn{3}{|l|}{ Forearm cortical bone density: } \\
\hline Before treatment $(\mathrm{cm})$ & $2 \cdot 41(0 \cdot 09)$ & $2 \cdot 63(0.07)$ \\
\hline$\%$ Change after treatment & $-0 \cdot 8(0 \cdot 7)$ & $-2 \cdot 4(1 \cdot 6)$ \\
\hline
\end{tabular}

No significant differences existed between groups (Mann-Whitney U test). the untreated or treated groups (table III). When extremes of calcium intake were examined no significant differences in the change in any bone measurement were observed between the groups with low and high intakes in either the treated (table II) or untreated women, though the number of untreated women was small.

\section{Discussion}

Our cross sectional study clearly showed that there was no relation between current dietary intake of calcium and calcium in bone in postmenopausal women. The concept of reduced calcium intake from either dietary deficiency or intestinal malabsorption causing osteoporosis was proposed many years ago. ${ }^{2}$ Since then data have both supported and refuted this hypothesis. Garn studied large populations and concluded that bone loss in adults is not a result of low or inadequate calcium intake..$^{1314}$ Conversely a study of two populations in Yugoslavia, one with a high and the other with a low intake of calcium, found a greater bone mass in the group with a high intake, although this difference tended to disappear after the menopause. ${ }^{15}$ Both studies were cross sectional and assessed bone mass by radiogrammetry, a technique that does not take into account changes in intracortical porosity and excludes trabecular bone. Racial differences could also have influenced their findings, and the Yugoslavian groups differed in other aspects of nutrition, including intakes of protein, fat, phosphorus, and energy. Although Matkovic et al also observed a higher incidence of fractures of the neck of the femur in the group with a low intake of calcium, there was no difference in the incidence of other osteoporotic fractures. ${ }^{\text {is }} \mathrm{A}$ difference in the incidence of fractures of the neck of the femur has been observed in populations with similar intakes of calcium and attributed to intake of fluoride. ${ }^{16}$

A study that used more sophisticated techniques to measure bone suggested that a high dietary intake of calcium during childhood results in a small but significantly greater bone density after the menopause, but the study examined only peripheral cortical bone and could simply have reflected better general nutrition in childhood. ${ }^{17}$ Another study of elderly women showed that a hich intake of calcium throughout their lives resulted in increased bone density in the midshaft of the forearm but had no effect on bone density in the distal forearm, which is clinically more important. ${ }^{18}$ Similarly, no influence of calcium intake on vertebral trabecular bone density was found in a cross sectional assessment ${ }^{19}$; this agrees with our findings. We recognise that cross sectional assessments of dietary intake of calcium may not reflect previous dietary habits, although there is some relation between current dietary consumption of calcium and lifelong intake. ${ }^{17}$ From our present study we cannot comment on any effects of nutritional influences during growth on the bone mass of adults. There is no doubt, however, that good nutrition, including a good intake of calcium, is beneficial during linear skeletal growth.

The influence of calcium intake on postmenopausal bone loss also remains controversial. From studies of

TABLE III-Correlation coefficients between dietary intake of calcium and changes in bone density in postmenopausal women given placebo or treatment

\begin{tabular}{|c|c|c|c|c|c|c|}
\hline & \multicolumn{2}{|c|}{ Dietary intake of calcium } & \multicolumn{2}{|c|}{ Vertebral bone density } & \multicolumn{2}{|c|}{ Forearm trabecular density } \\
\hline & Placebo & Treatment & Placebo & Treatment & Placebo & Treatment \\
\hline $\begin{array}{l}\text { Vertebral bone density } \\
\text { Forearm trabecular bone density } \\
\text { Forearm cortical bone density }\end{array}$ & $\begin{array}{l}-0 \cdot 33(n=16) \\
-0 \cdot 12(n=11) \\
-0 \cdot 05(n=15)\end{array}$ & $\begin{array}{l}-0.28(n=38) \\
-0.21(n=33) \\
-0.25(n=36)\end{array}$ & $\begin{array}{r}0.08(n=11) \\
-0.34(n=15)\end{array}$ & $\begin{array}{l}0 \cdot 13(\mathrm{n}=33) \\
0 \cdot 16(\mathrm{n}=36)\end{array}$ & $-0.05(n=11)$ & $0.29(n=33)$ \\
\hline
\end{tabular}

None of correlations were significant (Spearman's rank correlation coefficient). 
calcium balance Heaney et al suggested that a daily dietary intake of $1500 \mathrm{mg}$ calcium would maintain skeletal mass in postmenopausal women. ${ }^{20}$ This conclusion was derived from a projection of a regression analysis between intake of calcium and calcium balance that had not yielded a significant result. Furthermore, the methods used in calcium balance studies are subject to inaccuracies, particularly incomplete recovery of calcium output, which can produce the artefact of a positive shift in calcium balance. For example, calcium taken as milk supplements by postmenopausal women had no effect on bone loss (assessed by single photon absorptiometry) even though the calcium balance became more positive..$^{21}$ This emphasises the limitations of calcium balance studies and the necessity for direct skeletal measurements.

Using peripheral photon absorptiometry, Nilas et al were unable to show any influence of dietary intake of calcium on peripheral bone loss after the menopause. Other studies have shown that calcium supplementation slows but does not prevent postmenopausal bone loss. ${ }^{34}$ Radiogrammetry and peripheral photon absorptiometry, which were used in these studies, lack the sensitivity of axial measurements, ${ }^{22}$ and this may explain the inconsistent results. More recently a prospective study examined the effect on bone loss of a large $(2 \mathrm{~g})$ calcium supplement given early after the menopause." A slowing of the loss was seen in the midshaft of the radius, but there was no effect in the sites subject to osteoporotic fracture (the distal radius and vertebrae).

A study using quantitative computed tomography of the spine showed no effect on trabecular bone from supplementing the daily dietary intake of calcium up to $1500 \mathrm{mg}$ daily or more."2 A recent study also found no influence of dietary intake of calcium on rates of axial or appendicular bone loss in women over periods of up to six years..$^{23}$ Our limited results obtained over one year in women given a placebo confirm these findings. Nevertheless, calcium supplementation seems to be a fairly standard component of most treatment regimens aimed at preventing postmenopausal bone loss and hence osteoporosis. One reason for this may be the belief that calcium is non-toxic and inexpensive. Belief in the beneficial effects of calcium supplementation is generally without scientific foundation, as most studies that have examined the effects of calcium when it is added to other treatments have not included appropriate control groups. For example, Ettinger et al reported an additive effect on preventing bone loss when dietary supplementation of calcium was given to women receiving hormone replacement after the natural menopause. ${ }^{22}$ The study showed that $0.3 \mathrm{mg}$ conjugated equine oestrogens in combination with calcium supplementation was as effective as $0.6 \mathrm{mg}$ conjugated equine oestrogens alone, but the effects of $0.3 \mathrm{mg}$ conjugated equine oestrogens alone were not determined. Although Ettinger et al have shown that $0.3 \mathrm{mg}$ conjugated equine oestrogens alone is insufficient to prevent bone loss in women after oophorectomy, ${ }^{24}$ such women lose bone more quickly than women who have had a natural menopause. Our data show that intake of calcium does not influence the rate of bone loss after the menopause in women receiving effective treatment regimens including hormone replacement. Whether calcium supplements augment the effects of suboptimal treatment regimens remains to be determined.

Assessments of dietary intake of calcium are of limited accuracy unless made over long periods, but because we obtained detailed measurements of bone in subjects with high and low intakes of calcium we would expect our study to have shown an effect of calcium on bone if it existed. We were unable to show that the dietary intake of calcium soon after the menopause determines the postmenopausal bone state or, more importantly, its rate of loss. Furthermore, we did not find that the dietary intake of calcium influenced the response of bone to treatment. Suggestions that a high intake is either effective in preventing postmenopausal osteoporosis or an important adjunct to hormone replacement treatment seem to be without foundation. The calcium intake necessary for postmenopausal women may have been overestimated, and prophylaxis with calcium supplements alone seems to create a false sense of security. These supplements seem to be of commercial rather than clinical benefit.

We thank Mrs R Simpson for statistical advice. These studies were largely supported by grants from Ciba-Geigy UK and Laboratoires Besins-Iscovesco to Professor I MacIntyre, Royal Postgraduate Medical School, to whom we are grateful. The financial support of the Imperial Cancer Research Fund Laboratories to MIW and JAE is gratefully acknowledged. The computed tomography scanner was donated by the Bernard Sunley Trust.

1 Stevenson JC, Whitehead MI. Postmenopausal osteoporosis. Br Med $\mathrm{J}$ 1982;285:585-8.

2 Nordin BEC. Osteomalacia, osteoporosis and calcium deficiency. Clin Orthop $1960 ; 17: 235-57$

3 Horsman A, Gallagher JC, Simpson M, Nordin BEC. Prospective trial of oestrogen and calcium in postmenopausal women. Br Med f 1977;ii: 789-92.

4 Recker RR, Saville PD, Heaney RP. Effect of estrogens and calcium carbonate on bone loss in postmenopausal women. Ann Intern Med 1977;87:649-55.

on bone loss in postmenopausal women. Ann Intern Med 1977;87:649-55.
5 Nilas L, Christiansen C, Rodbro P. Calcium supplementation and postmenopausal bone loss. Br Med F 1984;289:1103-6.

6 Riis B, Thomsen K, Christiansen C. Does calcium supplementation prevent postmenopausal bone loss? N Engl f Med 1987;316:173-7.

7 Anonymous. Calcium supplements: does the milkman know best [Editorial]. Lancet 1987;i:370.

8 Stevenson JC. The pathogenesis of postmenopausal bone loss and osteoporosis. In: Fioretti P, Flamigni C, Jasonni VM, Melis GB, eds. Postmenopausol hormonal therapy: benefits and risks. New York: Raven Press, 1987:229-33.

9 Stevenson JC, Banks LM, Spinks TJ, et al. Regional and total skeleta measurements in the early postmenopause. 7 Clin Invest 1987;80:258-62.

10 Spinks TJ. Effect of size and composition of the body on absolute measurements of calcium in vivo. Phys Med Biol 1979;24:976-87.

11 Banks LM, Stevenson JC. Modified method of spinal computed tomography for trabecular bone mineral measurements. F Comput Assist Tomogr 1986;10 463-7.

12 Exner GU, Prader A, Elsasser U, Ruegsegger P, Anliker M. Bone densitometry using computed tomography. 1. Selective determination of trabecula bone density and other bone mineral parameters: normal values in children and adults. Br f Radiol 1979;52:14-23.

13 Garn SM. The earlier gain and later loss of cortical bone in nutritional perspective. Springfield: C.C.Thomas, 1970.

14 Garn SM, Soloman MA, Friedl J. Calcium intake and bone quality in the elderly. Ecology of Food and Nutrition 1981;10:131-3.

15 Matkovic V, Kostial K, Simonovic I, Buzina R, Brodarec A, Nordin BEC Bone status and fracture rates in two regions of Yugoslavia. Am 7 Clin Nutr 1979;32:540-9.

16 Simonen O, Laitinen O. Does fluoridation of drinking-water prevent bone fragility and osteoporosis? Lancet 1985;ii:432-4.

17 Sandler RB, Slemenda CW, LaPorte RE, et al. Postmenopausal bone density and milk consumption in childhood and adolescence. Am $\mathcal{F}$ Clin Nutr and milk consum

18 Anderson JJB, Tylavsky FA. Diet and osteopenia in elderly caucasian women. In: Christiansen C, Arnaud CD, Nordin BEC, Parfitt AM, Peck WA, Riggs BL, eds. Osteoporosis. Glostrup: Glostrup Hospital, 1984:299-304.

19 Laval-Jeantet AM, Paul G, Bergot C, Lamarque JL, N'Ghiania M. Correlation between vertebral bone density measurement and nutritional status. In Christiansen C, Arnaud CD, Nordin BEC, Parfitt AM, Peck WA, Riggs BL, eds. Osteoporosis. Glostrup: Glostrup Hospital, 1984:305-9.

20 Heaney RP, Recker RR, Saville PD. Menopausal changes in calcium balance performance. 7 Lab Clin Med 1978;92:953-63.

21 Recker RR, Heaney RP. The effect of milk supplements on calcium metabolism, bone metabolism and calcium balance. Am f Clin Nut 1985;41:254-63.

22 Ettinger B, Genant HK, Cann CE. Postmenopausal bone loss is prevented by treatment with low-dosage estrogen with calcium. Ann Intern Med 1987;106: 40-5.

23 Riggs BL, Wahner HW, Melton LJ, Richelson LS, Judd HL, O'Fallon WM Dietary calcium intake and rates of bone loss in women. $\mathcal{f}$ Clin Invest 1987;80:979-82.

24 Genant HK, Cann CE, Ettinger B, Gordan GS. Quantitative computed tomography of vertebral spongiosa: a sensitive method for detecting early bone loss after oophorectomy. Ann Intern Med 1982;97:699-705.

Accepted 4 March 1988 